\section{CHALLENGES IN DATA POOLING}

1,2Ann C Olsson* 1,2Saloshni Naidoo. 'International Agency for Research on Cancer, Lyon, France; ${ }^{2}$ Department of Occupational and Environmental Health, Nelson R. Mandela School of Medicine, University of KwaZulu-Natal, Congella, Durban, South Africa

10.1136/oemed-2018-ICOHabstracts.350

Aim Studying the effects of rare exposures in relation to rare diseases is challenging. In this session we will discuss problems and benefits with pooling data in epidemiological studies. We will show different examples of different types of pooling projects as well as results from those, and point to the contrasts with meta-analyses and multi-centre studies.

Eero Pukkala ${ }^{1}$, Deborah Glass ${ }^{2}$, Maria Leon Roux ${ }^{3}$, Hans Kromhout $^{4}$, Ann Olsson ${ }^{3}$, Ingrid S. Mehlum ${ }^{5}$

${ }^{1}$ Finnish Cancer Registry - Institute for Statistical and Epidemiological Cancer Research, Helsinki, Finland

${ }^{2}$ Monash University Centre for Occupational and Environmental Health, Department of Epidemiology and Preventive Medicine, Faculty of Medicine, Nursing and Health Sciences, Melbourne, Australia

${ }^{3}$ International Agency for Research on Cancer, Lyon, France

${ }^{4}$ Environmental Epidemiology Division, Institute for Risk Assessment Sciences, Utrecht University, Utrecht, The Netherlands

${ }^{5}$ National Institute of Occupational Health (STAMI), Oslo, Norway

\section{$1673 a$ ENTIRE POPULATIONS OF FIVE COUNTRIES AS AN OCCUPATIONAL STUDY COHORT - DOES IT WORK?}

E Pukkala. Finnish Cancer Registry - Institute for Statistical and Epidemiological Cancer Research, Helsinki, Finland

\subsection{6/oemed-2018-ICOHabstracts.351}

The Nordic Occupational Cancer (NOCCA) project was the largest and in many aspects, also qualitatively, the most unique research study ever done on occupation and cancer incidence. It consisted of a follow-up study on the entire working populations of Denmark, Island, Finland, Norway and Sweden with three million cancer cases diagnosed 1961-2005. It described risks of 84 cancer types in 54 occupational categories (astra. cancer.fi/NOCCA) and developed a Nordic Job Exposure Matrix (NOCCA-JEM) that converts the individual job histories of all Nordic people to quantitative estimates of exposure to potentially cancer-related factors. Many of the results on dose-response associations between exposures and cancers have been novel findings or have confirmed (or not) findings from earlier smaller studies. The NOCCA network still produces about one new publication each month from the old data. Still, not only the NOCCA researcher team but also institutions such as Nordic Minister Council and occupational health professionals have stressed that it would be important to continue NOCCA research work with updated data. New features in the work life, such as effects of sedentary work, could not be fully studied in the original NOCCA data. There is also an urgent need to follow effects of work safety regulations and operations that were started after the harmful effect of work carcinogens were recognised. For example, restaurant workers who had the highest risk of many cancers are no longer exposed to tobacco smoke in their work environment; this should be seen as a rapid decrease in their cancer risk. It has been proven that combining five entire national populations as a study cohort about 10 years ago was feasible and produced important results. The researchers of the NOCCA network are eager to continue and update the activity, provided that challenges related to funding and data access issues can be won.

\section{3b THREE NESTED CASE CONTROL STUDIES FROM COHORTS OF PETROLEUM INDUSTRY WORKERS}

DC Glass. Monash University Centre for Occupational and Environmental Health, Dept. of Epidemiology and Preventive Medicine, Faculty of Medicine, Nursing and Health Sciences, Melbourne, Australia

\subsection{6/oemed-2018-ICOHabstracts.352}

We pooled data from three nested case control studies from cohorts of Canadian, British and Australian petroleum industry workers and were able to examine relatively rare outcomes such as myelodysplastic syndrome (MDS) and myeloproliferative disease (MPD). The exposure assessment methodology was similar for all three studies. We examined the base estimates attributed to specific jobs before pooling the data and made some adjustments, notably to the background exposures attributed to individuals. In some cases the differences in exposure were explained by different circumstances, e.g. legal requirements. These inter-study comparisons were made blind as to case-status and before the data were pooled and the analyses were carried out. Multivariate analyses were used to identity main predictors of exposure intensity in ppm benzene. Site type (terminal, refinery, upstream) job (e.g. office terminal operator craft worker) and decade were strong predictors of exposure. Study was also a predictor of exposure which was of concern but the three studies covered different industry sectors (and hence jobs) and different decades. We therefore sought site type/jobs and decades which were represented in all three studies. There was little overlap with sufficient numbers to carry out such a comparison, with the exception of terminal workers in four job categories. We showed that job and era were significant predictors of exposure intensity but study was not a major predictor although the interaction terms study $\mathrm{X}$ job and study $\mathrm{X}$ decade were significant predictors of exposure intensity. Data pooling is more powerful than meta-analyses, allowing analyses by new metrics or new groupings perhaps derived from findings from one study which can be tested in a larger setting. Careful comparisons of data sets before they are pooled are essential to provide reassurance in the quality of the pooled data set and aid interpretation of pooled analyses.

\section{C DATA AVAILABILITY AND DATA POOLING EFFORTS IN THE AGRICOH CONSORTIUM}

ME Leon Roux. International Agency for Research on Cancer, Lyon, France

\subsection{6/oemed-2018-ICOHabstracts.353}

AGRICOH is an international consortium of agricultural cohort studies co-coordinated by the International Agency for Research on Cancer in France, and the National Cancer Institutes in the USA, to encourage and support data sharing to study disease-exposure associations for which data pooling 